\title{
Systematic review of evidence and consensus on perianal fistula: an analysis of national and international guidelines
}

\section{E. J. de Groo**, V. N. Cabral*, C. J. Buskens*, D. G. Morton†, D. Hahnloserł, W. A. Bemelman* and on behalf of the research committee of the European Society of Coloproctology}

*Department of Surgery, Academic Medical Center, Amsterdam, The Netherlands, †Academic Department of Surgery, University of Birmingham, Birmingham, UK and $\ddagger$ Department of Visceral Surgery, University Hospital CHUV, Lausanne, Switzerland

Received II June 2015; accepted 4 January 20 I6; Accepted Article online 5 February 2016

\begin{abstract}
Aim Treatment of perianal fistula has evolved with the introduction of new techniques and biologicals in Crohn's disease (CD). Several guidelines are available worldwide, but many recommendations are controversial or lack high-quality evidence. The aim of this work was to provide an overview of the current available national and international guidelines for perianal fistula and to analyse areas of consensus and areas of conflicting recommendations, thereby identifying topics and questions for future research.

Method MEDLINE, EMBASE and PubMed were systematically searched for guidelines on perianal fistula. Inclusion was limited to papers in English less than 10 years old. The included topics were classified as having consensus (unanimous recommendations in at least two-thirds of the guidelines) or controversy (fewer than three guidelines commenting on the topic or no consensus) between guidelines. The highest level of evidence was scored as sufficient (level 3a or higher of the
\end{abstract}

Oxford Centre for Evidence-based Medicine Levels of Evidence 2009, http://www.cebm.net/oxford-centreevidence-based-medicine-levels-evidence-march-2009/) or insufficient.

Results Twelve guidelines were included and topics with recommendations were compared. Overall, consensus was present in 15 topics, whereas six topics were rated as controversial. Evidence levels varied from strong to lack of evidence.

Conclusion Evidence on the diagnosis and treatment of perianal fistulae (cryptoglandular or related to $\mathrm{CD}$ ) ranged from nonexistent to strong, regardless of consensus. The most relevant research questions were identified and proposed as topics for future research.

Keywords Perianal fistula, guideline, review, consensus

\section{Introduction}

Perianal fistula is common. It can originate from infection of a cryptoglandular gland [1]. Other aetiologies include Crohn's disease (CD), malignancy, radiation, trauma or foreign body. Management requires the availability of specialist imaging and a detailed understanding of perianal anatomy and pathology, especially for complex fistulae. Treatment of fistula associated with CD has changed since the introduction of biologicals, with a reduced tendency towards surgery. New

Correspondence to: Professor Dr W. A. Bemelman, Academic Medical Center, Department of Surgery, PO Box 22660, II00 DD Amsterdam, The Netherlands.

E-mail: w.a.bemelman@amc.uva.nl surgical techniques have been introduced, such as the ligation of the intersphincteric fistula track (LIFT) procedure [2].

Many guidelines have been published with recommendations on diagnosis and surgical and medical management of cryptoglandular and Crohn's perianal fistula, but many of these are controversial or lack high-quality evidence. Some of the controversies can be explained by the persistence of guidelines that have become outdated because new medical and surgical therapies have since been introduced.

The aim of this study was systematically to review all the available international guidelines on perianal fistula and to provide an overview of the consensus and strength of the evidence for their recommendations for 
diagnosis and treatment. In addition, topics and questions for future research were sought.

\section{Method}

A systematic search of the literature on national and international guidelines for perianal fistula was performed by two independent researchers (E.J.deG. and V.N.C.). The final search was performed on 22 August 2014 and updated on 30 September 2015. The following databases were searched: MEDLINE, EMBASE and PubMed.

\section{Search terms}

The MeSH terms and free text used in various forms and combinations were assembled with a medical librarian. The terms used were 'rectal fistula' or 'perianal fistula' or 'anal fistula' or 'Crohn's disease' and 'guideline' or 'consensus'. Details are provided in the Appendix.

\section{Selection and data extraction}

The reviewers separately screened the retrieved hits on titles and abstracts, and then discussed them together. In the event of disagreement, a third reviewer (C.J.B.) was involved. Guidelines on perianal fistula were considered for inclusion. Papers for inclusion were limited those in English and less than 10 years old. Furthermore, guidelines alone based on evidence or grades of recommendation were considered for inclusion. The two reviewers independently extracted data from the included studies.

\section{Consensus and levels of evidence}

All topics discussed in the guidelines and followed by recommendations were included. They varied from diagnosis to surgical and medical therapy and the guideline recommendations were compared and classified as consensus or controversy. Consensus was defined as a topic discussed by at least two-thirds of the guidelines that achieved similar recommendations. Controversy was defined as a topic discussed by fewer than three guidelines or if there was no consensus. For each topic, the highest level of evidence available in the guidelines was determined and classified as sufficient if defined by a level of evidence 3 a or higher according to the Oxford Centre for Evidence-based Medicine Levels of Evidence 2009 (http://www.cebm.net/oxford-centre-evidencebased-medicine-levels-evidence-march-2009/), or insufficient if defined by any lower level (Tables 1 and 2 ). If the recommendations were not reported in the format of the Oxford Centre for Evidence-based Medicine
Levels of Evidence 2009 we manually reassigned the level of evidence according to this system as shown in Tables 1 and 2. The topics of interest for future research were discussed in a plenary session during the 9th European Society of Coloproctology (ESCP) meeting held in Barcelona in 2014.

\section{Results}

\section{Search}

After the removal of duplicates the initial search identified 384 studies (Fig. 1). Titles and abstracts were then screened, after which 79 potentially eligible publications remained. After assessment of these full text publications, 12 studies were included in the review [3-14]. One guideline was excluded because it was published over 10 years previously and nine were excluded as they were not in English. None of the other excluded guidelines contained any recommendations or levels of evidence.

\section{Included guidelines}

Of the 12 guidelines included, nine were specifically on Crohn's anal fistula, one on cryptoglandular fistula and two on both forms of fistula. The guidelines included were those published by the British Society of Gastroenterology (BSG), the Association of Coloproctology

Table I Levels of evidence for studies on aetiology, prevention and therapy. From: Oxford Centre for Evidence-based Medicine Levels of Evidence 2009 (http://www.cebm.net/oxford-centre-evidence-based-medicine-levels-evidence-march$2009 /)$.

\begin{tabular}{|c|c|}
\hline $\begin{array}{l}\text { Level of } \\
\text { evidence }\end{array}$ & \\
\hline la & $\begin{array}{l}\text { Systematic review (with homogeneity) of } \\
\text { randomized controlled trials }\end{array}$ \\
\hline $1 b$ & $\begin{array}{l}\text { Individual randomized controlled trial } \\
\text { (with narrow confidence interval) }\end{array}$ \\
\hline $2 \mathrm{a}$ & $\begin{array}{l}\text { Systematic review (with homogeneity) of } \\
\text { cohort studies }\end{array}$ \\
\hline $2 b$ & $\begin{array}{l}\text { Individual cohort study (including } \\
\text { low-quality randomized controlled trials) }\end{array}$ \\
\hline $3 a$ & $\begin{array}{l}\text { Systematic review (with homogeneity) of } \\
\text { case-control studies }\end{array}$ \\
\hline $3 b$ & Individual case-control studies \\
\hline 4 & $\begin{array}{l}\text { Case series (and poor quality cohort and } \\
\text { case-control studies) }\end{array}$ \\
\hline 5 & $\begin{array}{l}\text { Expert opinion without explicit critical } \\
\text { appraisal or based on physiology, bench } \\
\text { research or 'first' principles }\end{array}$ \\
\hline
\end{tabular}


Table 2 Levels of evidence for studies on diagnostics. From: Oxford Centre for Evidence-based Medicine Levels of Evidence 2009 (http://www.cebm.net/oxford-centre-evidence-basedmedicine-levels-evidence-march-2009/).

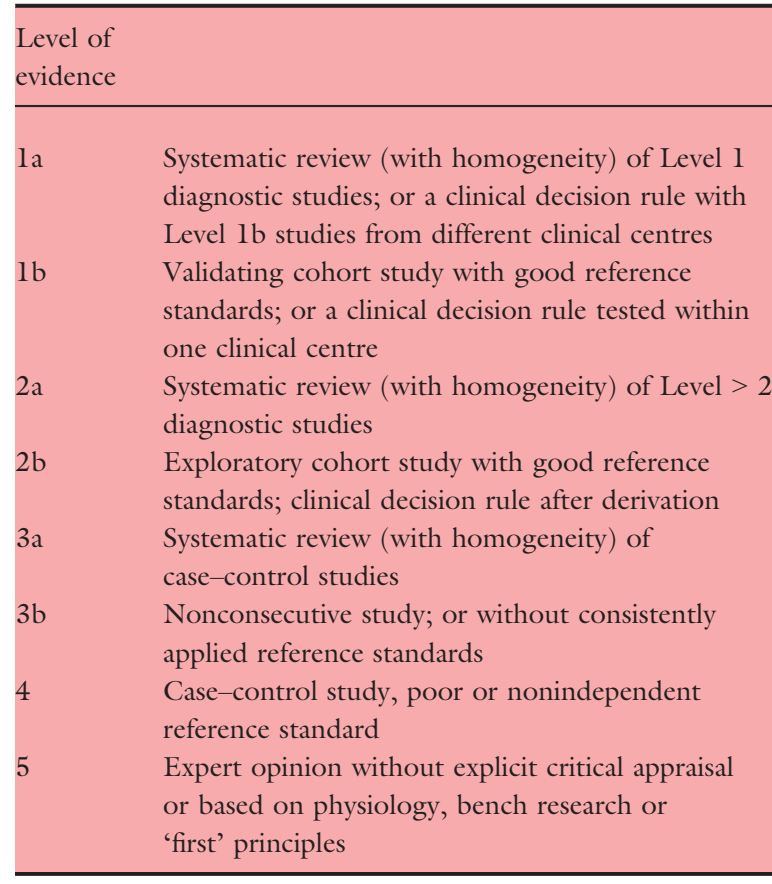

of Great Britain and Ireland (ACPGBI), the Canadian Association of Gastroenterology (CAG), the Brazilian Study Group of Inflammatory Bowel Diseases (BSGIBD), the Danish Society of Gastroenterology (DSG), the European Crohn's and Colitis Organisation - Special Situations (ECCO), the Italian Society of Gastroenterology (SIGE), the German S3 guideline: cryptoglandular anal fistulas (CAF), the American College of Gastroenterology (ACG), the American Society of Colon and Rectal Surgeons (ASCRS), the Japanese Society of Gastroenterology (JSG) and the Shanghai Working Group (SWG) (Table 3) [3-14].

Overall, consensus was reached in 15 topics. The comparative findings from the included guidelines are summarized in Table 4.

\section{Statements}

\section{Diagnostics}

\section{Magnetic resonance imaging}

Of the included guidelines, seven advocated MRI for the assessment of perianal Crohn's and cryptoglandular fistula. The ASCRS guideline strongly recommended the use of MRI. The ACPGBI and the ECCO guidelines were more specific, stating that MRI should be con- sidered in all complex (including recurrent) fistulae. For a simple fistula MRI was not considered to be routinely necessary. Similar recommendations were given in the SIGE and BSGIBD guidelines. The SWG considered MRI to be the gold standard of imaging for perianal fistula in CD. Four guidelines stated that endoscopy, MRI, anorectal ultrasound and examination under anaesthesia (EUA) should be combined to increase the diagnostic accuracy to determine the best treatment strategy.

- Conclusion: The use of MRI for diagnosing and mapping of perianal fistula is recommended. Consensus, highest level of evidence la [15-17].

\section{Anorectal ultrasound}

The use of anorectal ultrasound was discussed in seven guidelines. The ACPGBI stated that this technique may be the first-line investigation for patients with a recurrent fistula or one suspected to be complex. The accuracy of anorectal ultrasound was highly dependent on the expertise of the examiner, according to the ECCO, SIGE and CAF guidelines.

- Conclusion: Anorectal ultrasound requires expertise of the examiner, but can be an accurate procedure to determine the anatomical pathology of perianal fistula. Consensus, highest level of evidence la [18-21].

\section{Examination under anaesthesia}

EUA was mentioned and recommended in seven guidelines. Some (ECCO and SIGE) considered it to be the gold standard when performed by an experienced colorectal surgeon. The ECCO and SWG guidelines stated that in patients with an anorectal abscess drainage was the priority. Accordingly EUA should precede imaging by MRI or anorectal ultrasound unless these can be performed without delay. The ACPGBI, CAF and ASCRS guidelines considered digital examination to be a useful tool, but none mentioned that this should be conducted under anaesthesia.

- Conclusion: Examination under anaesthesia has an important role in the diagnosis and classification of perianal fistula. Consensus, highest level of evidence lb $[17,19]$.

\section{Endoscopy}

Only three (ECCO, SIGE and SWG) guidelines on Crohn's perianal fistula included endoscopy. All stated that rectoscopy should be performed at the initial evaluation since proctitis is of crucial importance for the choice of therapy. In some case endoscopy may demonstrate the internal opening of a fistula.

- Conclusion: Endoscopic assessment of the rectosigmoid should be performed in patients with Crohn's 


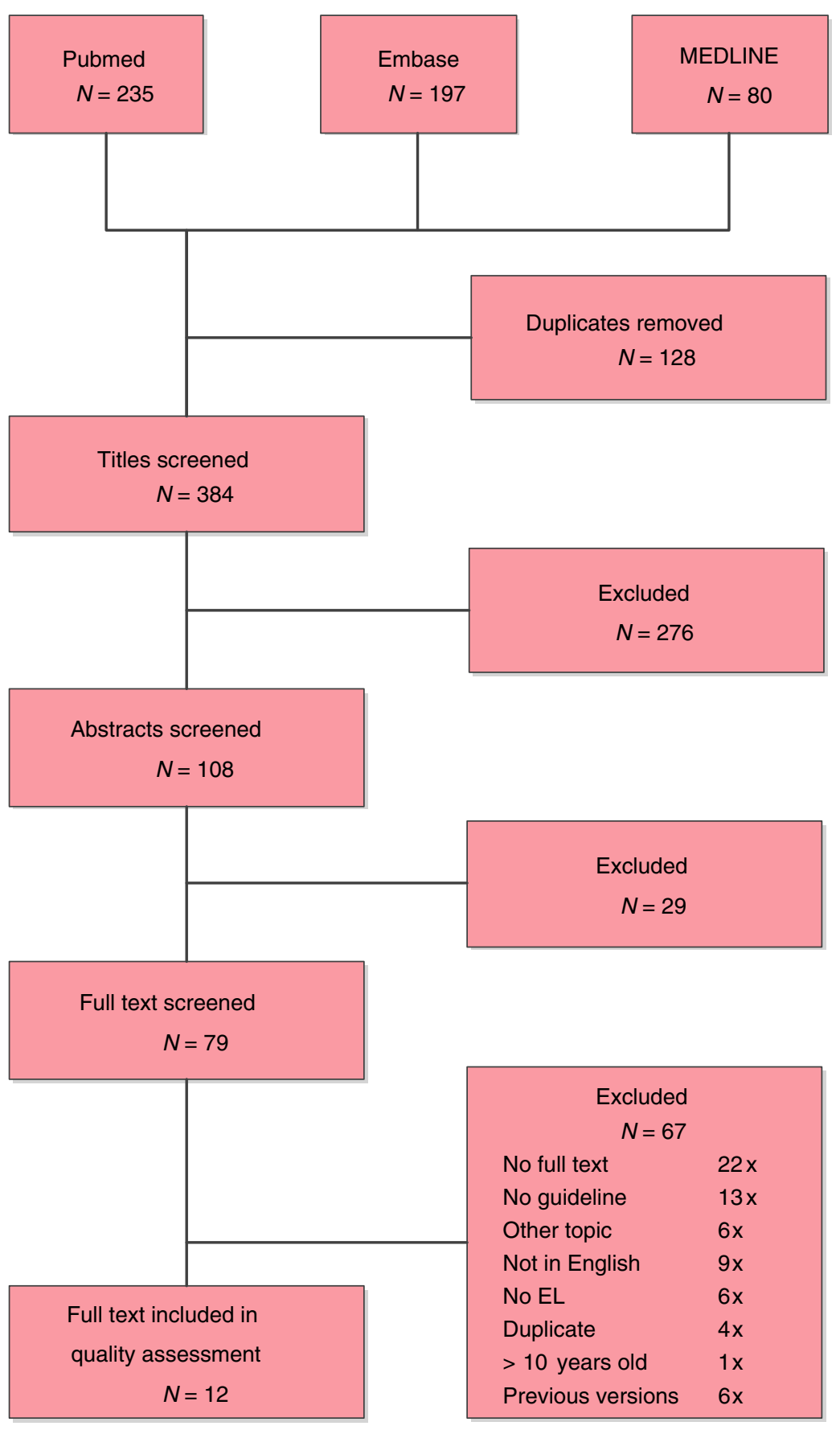

Figure I Flow chart of the systematic search and inclusion of guidelines. perianal fistula to determine the presence or absence of proctitis which will influence management. Consensus, highest level of evidence $2 b$ [22-25].

\section{Computed tomography}

Three guidelines (ACPGBI, ASCRS and SWG) included a statement on CT. The ACPGBI guideline recommended its use where MRI is not available or contraindicated. The ASCRS guideline recommended CT in patients with complex anorectal suppuration or in $\mathrm{CD}$, but the SWG guideline stated that the visualization of perianal anatomy was poor. CT required administration of oral and/or rectal contrast and patients are exposed to radiation. CT for perianal fistula now appears to be regarded as obsolete.

- Conclusion: CT for diagnosing perianal fistula is inferior to MRI and anorectal ultrasound. No consensus, highest level of $2 b[26,27]$. 
Table 3 Overview of the included guidelines.

\begin{tabular}{lllll}
\hline Guideline & Year & $\begin{array}{l}\text { Previous } \\
\text { versions }\end{array}$ & $\begin{array}{l}\text { Crohn's } \\
\text { fistulae }\end{array}$ & $\begin{array}{l}\text { Cryptoglandular } \\
\text { fistulae }\end{array}$ \\
\hline BSG [3] & 2004 & & Yes & No \\
ACPGBI [4] & 2007 & & Yes & Yes \\
CAG [5] & 2009 & 2001, & Yes & No \\
& & 2004 & & \\
BSGIBD [6] & 2010 & & Yes & No \\
DSG [7] & 2010 & & Yes & No \\
ECCO [8] & 2010 & 2006 & Yes & No \\
SIGE [9] & 2010 & & Yes & No \\
CAF [10] & 2011 & & No & Yes \\
ACG [11] & 2011 & & Yes & No \\
ASCRS [12] & 2011 & 1996, & Yes & Yes \\
& & 1997, & & \\
& & 2005 & & Yes \\
JSG [14] & 2012 & 2010 & No \\
SWG [13] & 2014 & & Yes & No \\
\hline
\end{tabular}

BSG, British Society of Gastroenterology; ACPGBI, Association of Coloproctology of Great Britain and Ireland; CAG, Canadian Association of Gastroenterology; BSGIBD, Brazilian Study Group of Inflammatory Bowel Diseases; DSG, Danish Society of Gastroenterology; ECCO, Crohn's and Colitis Organisation - Special Situations; SIGE, Italian Society of Gastroenterology; CAF, German S3 guideline: cryptoglandular anal fistulas; ACG, American College of Gastroenterology London Position Statement on Biological Therapy; ASCRS, American Society of Colon and Rectal Surgeons; JSG, Japanese Society of Gastroenterology; SWG, Shanghai Working group: World Gastroenterology Organization, International Organisation for Inflammatory Bowel Diseases, European Society of Coloproctology and Robarts Clinical Trials.

\section{Fistulography}

None of the five guidelines (ACPGBI, ECCO, SIGE, ASCRS, SWG) that commented on fistulography recommended its use. Some of the guidelines specifically stated that fistulography should not be recommended, whereas others only mentioned that it has a very limited role in the assessment of perianal fistula.

- Conclusion: Fistulography has a no role in the standard assessment of perianal fistula. Consensus, highest level of evidence 2 b [26-28].

\section{Classification}

The classification of perianal fistula was described in four of the twelve guidelines. Despite some variation, most mentioned two classification systems, including those described by Parks and the American Gastroenterology Association (AGA). Parks' classification defines four types of perianal fistula according to the relationship of the primary fistula track to the anal sphincter complex [29]. A classification distinguishing between simple and complex fistula was proposed by the AGA, although there was no clear definition of these. The ECCO guideline stated that Parks' classification is superior for surgical decision taking.

- Conclusion: There is no consensus which classification system should be used. No consensus, highest level of evidence $3 b[25,29]$.

- Conclusion: There is no clear definition of simple and complex fistula. No consensus, highest level of evidence $3 b[25,29]$.

\section{Surgery}

Simple drainage of an abscess with no evidence of simultaneous fistula formation may result in healing in about half of cases. In those with a concurrent fistula track, the aim of drainage in patients with acute abscess is drainage and prevention of recurrent abscess formation by the insertion of a seton.

In patients with a persisting perianal fistula after resolution of the acute phase, the management of cryptoglandular and CD-related fistula is different. In each case cure of the fistula has to be balanced with the preservation of faecal continence. In CD the ultimate goal is to improve quality of life and to avoid a stoma and proctectomy. Several surgical techniques are available for the treatment of perianal fistula, depending on its characteristics.

\section{Fistulotomy}

Fistulotomy was mentioned by eight guidelines and all stated it to be effective. In cryptoglandular fistula, fistulotomy is the most common surgical technique (CAF guideline), but there were some discrepancies regarding its indications. According to the DSG, ECCO, SIGE and ASCRS guidelines, only symptomatic simple perianal fistulae should be treated by fistulotomy. Furthermore, the ACPGBI and SWG guidelines only recommended fistulotomy for superficial or low fistulae (without proctitis in patients with $\mathrm{CD}$ ). In contrast, the ASCRS guideline stated that complex fistulae may be treated by staged fistulotomy provided that this is carefully considered, since there is an increased risk of incontinence, especially in female patients with an anterior fistula. The ACPGBI guideline also mentions a high incontinence rate after fistulotomy of more complex perianal fistulae with a high internal opening. Fistulectomy was addressed in some guidelines. The BSG recommended the use of fistulectomy for persistent or complex fistulae in CD combined with medical therapy. The SIGE guideline stated that fistulectomy should not be performed because of the risk of incontinence. 


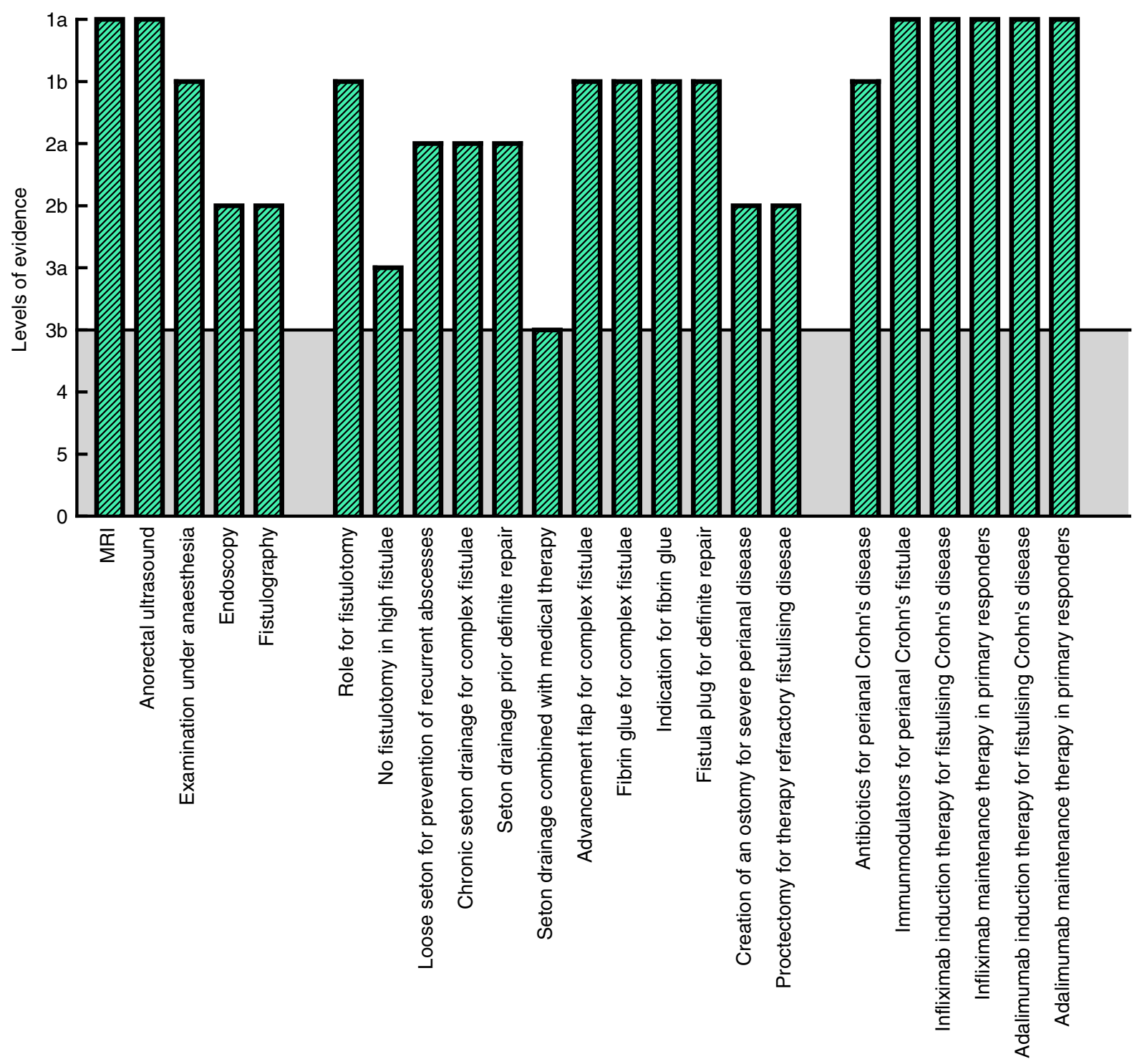

Topics

Figure 2 Topics on diagnostics, surgical and medical treatment for perianal fistula with consensus. Consensus was defined as unanimous recommendations in two-thirds of the guidelines commenting on included topics. A level of evidence of $3 \mathrm{a}$ or higher according to the Oxford Centre for Evidence-based Medicine Levels of Evidence 2009 was considered sufficient.

- Conclusion: There is an important role for fistulotomy in the treatment of perianal fistula. Consensus, highest level of evidence $1 \mathrm{~b}$ [30].

- Conclusion: Fistulotomy should in general not be used in high perianal fistulae. Consensus, highest level of evidence $3 \mathrm{a}$ [30-32].

\section{Cutting seton}

There were four guidelines commenting on the cutting seton. Only the ACPGBI guideline recommended its use for transsphincteric fistulae. Because this technique is associated with a high risk of incontinence it was strongly advised against by the CAF guideline [33].

- Conclusion: The use of the cutting seton is not advised because of the risk of incontinence. No consensus, highest level of evidence 2a [34,35].

\section{Loose seton}

In cryptoglandular disease setons are mostly reported as a temporary measure, whereas in CD they may be a first step in any form of treatment, medically or surgically. In $\mathrm{CD}$ the seton can also be used as a chronic therapy. 


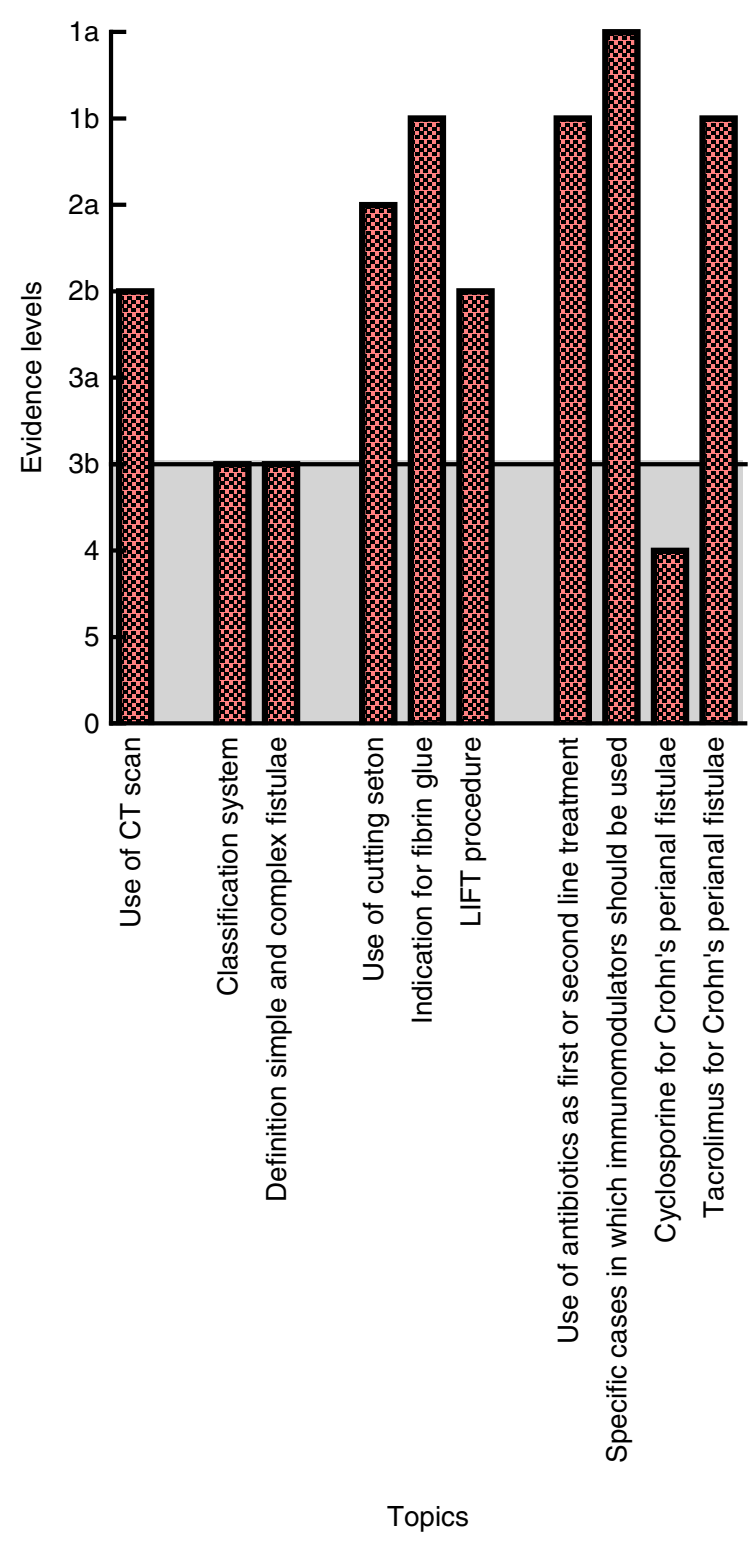

Figure 3 Topics on diagnostics, surgical and medical treatment for perianal fistulae without consensus (controversy). Controversy was defined as fewer than three guidelines commenting on a topic or no consensus between the guidelines on included topics. A level of evidence of $3 \mathrm{a}$ or higher according to the Oxford Centre for Evidence-based Medicine Levels of Evidence 2009 was considered sufficient.

The use of a loose seton for some cryptoglandular or CD fistulae was advised in all but the CAG guideline. For CD, it was recommended as a first step before medical or definitive surgery. In patients with a more complex fistula it is often necessary to leave the seton in place as maintenance therapy (ECCO and ASCRS guideline). The optimal timing of removal of the seton is, however, unknown. For a simple fistula in CD, the ECCO recommended seton insertion only for a symp- tomatic fistula, whereas the SIGE guideline stated that all simple fistulae should be treated with placement of a loose seton or fistulotomy.

- Conclusion: Loose seton placement is an effective treatment reducing the chance of recurrent abscess formation. Consensus, highest level of evidence $2 \mathrm{a}$ [35-39].

- Conclusion: Chronic loose seton drainage is an important alternative treatment for complex perianal fistula. Consensus, highest level of evidence $2 \mathrm{a}$ $[36,39]$.

- Some surgeons advise a loose seton before surgery aiming at cure. No consensus, highest level of evidence $2 \mathrm{a}[38]$.

- Conclusion: The combination of a loose seton with medical therapy is helpful in CD. Consensus, highest level of evidence $3 \mathrm{~b}$ [38].

\section{Rectal advancement flap}

Six guidelines included a statement on treatment by a rectal advancement flap and all stated that this technique may be used for the treatment of more complex Crohn's or cryptoglandular fistulae. In Crohn's perianal fistula, concomitant medical therapy with an immunosuppressant was advised (BSG and ECCO guideline).

- Conclusion: Advancement flap repair of cryptoglandular and Crohn's fistula is a technique that is often used for closure of the fistula. Consensus, highest level of evidence $1 \mathrm{~b}$ [40-44].

\section{Fibrin glue}

Six guidelines stated that the injection of fibrin glue down the primary track can be used in Crohn's and cryptoglandular perianal fistula. Several guidelines mentioned that this technique should still be evaluated by controlled studies. There were some discrepancies regarding the specific indication for fibrin glue treatment. The ACPGBI and the ASCRS guidelines stated that both simple and complex fistulae can be treated with fibrin glue injection, while the DSG and CAF stated that it should be utilized only for complex fistulae.

- Conclusion: There is a place for fibrin glue in the treatment of complex perianal fistulae, although the efficiency remains unclear. Consensus, highest level of evidence $1 \mathrm{~b}[37,45,46]$.

- Conclusion: It is unclear which patients should receive this treatment. Consensus, highest level of evidence $1 \mathrm{~b}[37,45,46]$.

\section{Fistula plug}

Five guidelines included a fistula plug. Although they stated that further research is required, a fistula plug may be used for definite fistula repair for Crohn's and 


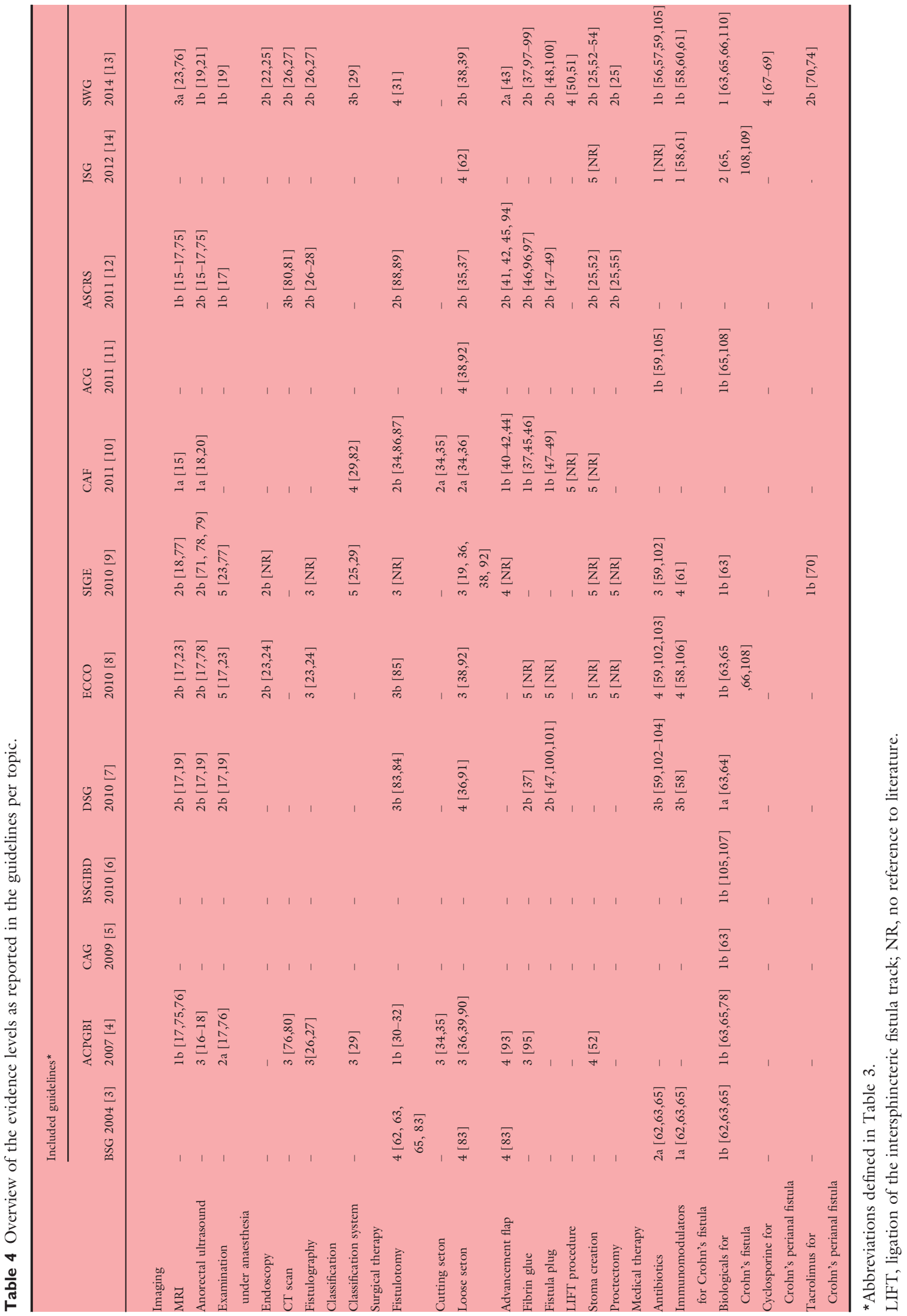


cryptoglandular fistula. The ECCO guideline stated that a fistula plug can be used in CD. The healing rate in the long term might be improved if used in combination with infliximab.

- Conclusion: Fistula plugs are a valid option for treating perianal fistula. Consensus, highest level of evidence $1 \mathrm{~b}[47-49]$.

\section{Ligation of the intersphincteric fistula track}

LIFT is a new technique and was mentioned in only three (CAF, ASCRS and SWG) guidelines, two of which included a level of evidence. All three stated that it may be an option for complex fistula, but that the data were too preliminary to draw conclusions.

- Conclusion: The LIFT procedure is an option for the treatment of perianal fistula in selected patients. No consensus, highest level of evidence $4[50,51]$.

\section{Stoma}

Creation of a defunctioning stoma was mentioned in eight guidelines, and all agreed that, depending on the severity and complexity of anorectal CD, a stoma may be required since this can rapidly restore quality of life and sometimes lead to remission on its own. A stoma should be reserved for exceptional cases. Unfortunately, intestinal continuity is often not restored, and eventually many patients with a stoma will require a proctectomy during the course of their disease.

- Conclusion: The creation of a defunctioning stoma is an option for patients with severe perianal fistulizing disease and may often be followed by a proctectomy. Consensus, highest level of evidence $2 b$ [25,52-54].

\section{Proctectomy}

Despite optimal medical and surgical treatment for anorectal CD some patients may eventually require a proctectomy. All five guidelines that commented on proctectomy stated that this may be necessary in patients with severe perianal fistulizing disease, but this should be considered as a last resort.

- Conclusion: A proctectomy is a last resort in patients with severe fistulizing anorectal CD that is refractive to therapy. Consensus, highest level of evidence $2 \mathrm{~b}$ $[25,55]$.

\section{Medical therapy}

The administration of medical therapy for a Crohn's perianal fistula aims at the reduction of symptoms and eventually closure, with improvement in quality of life. Prevention of recurrent abscess formation is of crucial importance for the patient. There are several medical treatment options. Symptom alleviation may be achieved with medical therapy, but definitive closure of perianal fistulae is rare, and unfortunately overall recurrence rates are high.

\section{Antibacterial agents}

Antibacterial agents such as nitroimidazoles (metronidazole and tinidazole) and antibiotics including ciprofloxacin and are widely used in perianal fistula. All seven guidelines commenting on antibacterial agents recommended their use, but there were some discrepancies in their indications. Some guidelines stated that antibacterial drugs are more suited as first-line treatment for simple fistulae, whereas others recommended them as a second-line treatment or for more complex fistulae. The combination of antibacterial agents with immunomodulators and/or biologicals for Crohn's perianal fistula was also recommended by several guidelines.

- Conclusion: Antibacterial agents are effective in the treatment of perianal fistulae in CD. Consensus, highest level of evidence $1 \mathrm{~b}$ [56-59].

- Conclusion: It is unclear whether antibacterial agents should be used as first-line or second-line treatment in both simple and complex fistulae. No consensus, highest level of evidence $1 \mathrm{~b}$ [56-59].

\section{Immunomodulators}

Seven guidelines mentioned the use of immunomodulators such as azathioprine and 6-mercaptopurine and were unanimous in recommending their use for Crohn's perianal fistula. The guidelines showed discrepancies in their indications. Some stated that immunomodulators were potentially effective in simple perianal fistula, whereas others indicated that they should be used in complex fistula as a second-line treatment. The ECCO and DSG guidelines indicated that immunomodulators should be used in combination with surgery, since when given alone they are rarely able to control the fistula.

- Conclusion: Immunomodulators are recommended in the medical management of perianal Crohn's fistula, but recent evidence is conflicting with respect to efficacy. Consensus, highest level of evidence la $[58,60$ $62]$.

- Conclusion: The specific indications for immunomodulators are unclear. No consensus, highest level of evidence la $[58,60-62]$.

\section{Biologicals}

Ten guidelines provided a statement regarding antitumour necrosis factor (TNF) therapy, mainly for infliximab $(n=10)$ and adalimumab $(n=8)$. All were in favour of biologicals as induction or maintenance therapy for a complex Crohn's perianal fistula. Combination therapy with biologicals and immunomodulators seemed to be more effective than monotherapy. 
- Conclusion: Infliximab is recommended for patients with fistulating CD. Consensus, highest level of evidence la $[63,64]$.

- Conclusion: In patients with fistulating CD who respond to induction therapy with infliximab, maintenance therapy is effective in maintaining fistula closure or other response. Consensus, highest level of evidence la $[64,65]$.

- Conclusion: Administration of adalimumab is recommended for patients with fistulizing CD. Consensus, highest level of evidence la $[64,66]$.

- Conclusion: In patients with fistulating CD who responded to induction therapy with adalimumab, maintenance therapy is effective. Consensus, highest level of evidence la $[64,66]$.

\section{Cyclosporine}

Cyclosporine for perianal fistula in CD was only mentioned by two guidelines, and both stated that the evidence for this treatment option was limited.

- Conclusion: The role of cyclosporine for treating Crohn's perianal fistula is limited. No consensus, highest level of evidence $1 \mathrm{~b}$ [67-69].

\section{Tacrolimus}

Tacrolimus has been used extensively in patients undergoing organ transplantation. It has subsequently been demonstrated to improve the outcome of inflammatory bowel disease (IBD) in patients having a liver transplant for primary sclerosing cholangitis (PSC). Of three guidelines which mentioned tacrolimus for Crohn's perianal fistula, two stated that it can be effective in treating active Crohn's fistula.

- Conclusion: Tacrolimus may be effective for Crohn's perianal fistula. No consensus, highest level of evidence $1 \mathrm{~b}[70]$.

\section{Topics with consensus and high-quality evidence}

\section{Diagnosis}

For imaging the guidelines strongly advised the use of MRI, with accuracy rates of more than 90\%. Anorectal ultrasound may also be used, with accuracy rates similar to MRI (56-100\%), especially when hydrogen peroxide was injected into the external opening, but the quality of imaging depended on the expertise of the examiner [17,71]. EUA played an important role in diagnosis and assessment, which influenced the nature of surgery. Combining imaging modalities increased diagnostic accuracy. Colonoscopy was advised in the initial evaluation of CD patients. Fistulography was traditionally the imaging technique of choice, but with an accuracy of less than $20 \%$ this technique was not favoured [26].

\section{Surgery}

Fistulotomy was advised for low perianal fistula, but should be avoided in complex (high) perianal fistula due to the risk of incontinence. The use of a cutting seton was strongly advised against, since it was associated with a high risk (57\%) of incontinence [33]. In contrast, insertion of a loose seton was recommended by all the guidelines, in combination with medical therapy in CD or as maintenance treatment in case of a complex cryptoglandular fistula. Most of the guidelines stated that an advancement flap may be used for the treatment of a complex fistula, with reported closure rates of approximately $80 \%$ and $60 \%$ in patients with cryptoglandular fistula and CD, respectively [43]. Fibrin glue and a fistula plug were also considered to be useful for a complex perianal fistula, although the guidelines stated that further research was required.

\section{Medical treatment}

Antibiotics are considered to be effective in the treatment of perianal fistula and septic complications in CD. Combining antibiotics with immunomodulators and/or biologicals for Crohn's perianal fistula was also recommended by most guidelines. A recent randomized placebo-controlled trial evaluated the effect of adding ciprofloxacin to adalimumab treatment for Crohn's perianal fistula. Combination therapy proved to be more effective in achieving closure $(P=0.047)$ [56]. The effect disappeared with the discontinuation of antibiotic therapy at week 24. A recent published meta-analysis combining the three above-mentioned studies revealed that ciprofloxacin was effective in achieving remission in patients with Crohn's perianal fistula (pooled relative risk $=1.66 ; 95 \% \quad$ CI $1.16-2.39 ; \quad P=0.006) \quad[72]$. Immunomodulators are recommended in the medical management of perianal CD, but there are no comparative studies and indirect evidence is derived from secondary end-points in clinical trials. Most of the guidelines considered the administration of biologicals to be helpful in patients with (complex) CD. Although several randomized controlled trials (RCTs) showed that induction and maintenance therapy with biologicals is effective in patients with Crohn's perianal fistula, efficacy is limited. Unfortunately, there was no statement on when anti-TNF medication can be stopped. The literature shows that $50 \%$ of fistulae reopened after cessation of medication after a median period of 3 months [73]. An overview of the topics with consensus is presented in Fig. 2. 


\section{Topics with consensus without high-quality evidence}

Stoma

Creation of a defunctioning stoma is an option in patients with severe perianal fistulizing disease, but it should be reserved for exceptional cases. Unfortunately, intestinal continuity is often not subsequently restored.

\section{Proctectomy}

Some patients with a stoma will require a proctectomy during the course of their disease, but this procedure should be considered as a last resort. An overview of the topics with consensus is presented in Fig. 2.

\section{Topics without consensus}

\section{Computed tomography}

The use of CT is considered helpful in some situations, for example when MRI is not available or when it is contraindicated. There are, however, some disadvantages of CT since it requires administration of oral and/or rectal contrast and patients are exposed to radiation. In addition, visualization of perianal anatomy is poor, and for these reasons CT is regarded as obsolete for the visualization of perianal fistula.

\section{Classification}

Most of the guidelines mentioned two classification systems including that of Parks and the American Gastroenterological Association (AGA). But there was no consensus on which system should be used. There was no clear definition of simple and complex fistula mentioned in the AGA guidelines.

\section{Loose seton placement prior to definite repair}

Insertion of a loose seton prior to definite surgical repair was not frequently mentioned, but in CD draining of all fistula tracks including the branches was regarded as an important first step.

\section{Ligation of intersphincteric fistula track}

The LIFT procedure is a new technique for the surgical management of transsphincteric fistula, and for this reason only two of the guidelines included a statement on this technique. LIFT can be an effective treatment for perianal fistulizing disease in selected patients.

\section{Specific Indication for antibiotics}

It is unclear whether antibiotics should be used as a first- or second-line treatment in both simple and complex fistulae, but in the absence of scientific evidence metronidazole and ciprofloxacin are widely used in the treatment of patients with perianal fistula.

\section{Specific Indications for immunomodulators}

It is unclear in which specific cases immunomodulators should be used. Some guidelines stated that immunomodulators are potentially effective in simple Crohn's fistula, whereas others indicated that it should be used in complex fistula as a second-line medical treatment.

\section{Cyclosporine}

The role of cyclosporine in Crohn's fistula is limited. Only a few uncontrolled case studies reported a rapid response to cyclosporine, but in these any response was rapidly lost after cessation of medication [67-69].

\section{Tacrolimus}

Tacrolimus may be effective for Crohn's perianal fistula, but only two guidelines mentioned this medication. A RCT was performed comparing tacrolimus with placebo and revealed a favourable effect on the improvement of symptoms, but there was no significant difference in remission at 4 weeks [70]. Another study assessing topical tacrolimus revealed no significant benefit [74]. An overview of the topics without consensus is presented in Fig. 3.

\section{Discussion}

In this review an overview of the current available national and international guidelines for perianal fistulae is provided to analyse areas of consensual and conflicting recommendations.

Overall, consensus was found in most topics. When there was failure to achieve consensus this was due to the fact that fewer than three guidelines commented on the specific topic. Some guidelines may have mentioned a topic but did not include any statement on level of evidence or recommendation.

All 12 of the included guidelines either used levels of evidence or grades of recommendation. Most topics had sufficient (level 3a or above) supporting evidence, but in the review process there were some difficulties regarding the actual level. Although there are several classifications of the quality of assessment of the literature, the assignment of a level of evidence is subjective, leading to variation in interpretation. First, the two reviewers did not always agree on the assigned level of evidence, and in this situation we simply reported the level of evidence stated in the guidelines. For example, the reported level of evidence on the use of tacrolimus was $1 b$, but this was based on one randomized controlled trial of only 48 patients. Secondly, when a level of evidence was assigned to a statement in the guidelines the relevant literature was often lacking. Some 
guidelines referred to other guidelines to find the evidence, which raised the question of what the evidence level of the guideline was. Other inconsistencies between guidelines and evidence levels were the result of when the guideline was published. Science is evolving, and newly published evidence and the development of surgical techniques and medical treatment need to be regularly updated. Multidisciplinary management of patients with Crohn's perianal fistula is of crucial importance to improve the outcome, but most guidelines deal with surgery and medical treatment separately. The SWG guideline was the most extensive in reviewing diagnosis as well as surgery and medical therapy.

Currently there are several ongoing trials mainly addressing the treatment options for perianal fistula. Several RCTs are being conducted for the treatment of cryptoglandular fistula. These include a study of the effect of adding stem cells to fibrin glue (NCT01803347) and of injection of platelet-rich plasma (PRP) into the fistula track combined with advancement flap for recurrent cryptoglandular fistula (NCT01615302). There are, furthermore, two ongoing trials comparing advancement flap with collagen plug insertion (NCT01021774) or LIFT (NCT01997645) for complex cryptoglandular fistula. For complex Crohn's perianal fistula, there is a trial comparing adipose tissue-derived stem cells with a placebo (NCT01541579). Another trial comparing chronic seton drainage, anti-TNF therapy or an advancement flap for Crohn's fistula has recently been initiated (NTR4137) with the primary end-point of the proportion of fistula-related interventions over time.

\section{Topics for further research}

Suggested topics for future research were discussed in a plenary session at the 9th ESCP annual meeting after presentation of the results of the present review (Table 5). It was agreed that a classification should be generally adopted, with no present consensus on whether Parks' classification or the more clinical subdivision of simple and complex fistula should be used, although there is no agreed definition of the terms 'simple' and 'complex'. There should be a surgical algorithm of the treatment options for the various types of fistula. The surgical and medical options used alone or in combination should be compared in patients with a Crohn's fistula. In the case of Crohn's fistula there is no guideline on when a seton should be removed after anti-TNF treatment and there is no recommendation on when anti-TNF treatment should be stopped. Evidence on the diagnosis and treatment of perianal fistula varies from strong to nonexistent. There
Table 5 Topics for further research.

\begin{tabular}{ll}
\hline Topic & Question \\
\hline Classification & $\begin{array}{l}\text { Definition of a simple or complex fistula } \\
\text { (both cryptoglandular and in } \\
\text { Crohn's disease) } \\
\text { Classification system to be used in } \\
\text { cryptoglandular fistulae } \\
\text { Surgical treatment algorithm with respect } \\
\text { to the available options }\end{array}$ \\
Medical therapy & $\begin{array}{l}\text { Timing of seton removal } \\
\text { When to stop anti-TNF therapy in } \\
\text { patients with Crohn's perianal fistula } \\
\text { Surgical vs medical }\end{array}$ \\
$\begin{array}{l}\text { Surgical } v s \text { medical } v \text { combination } \\
\text { options in the treatment of } \\
\text { Crohn's fistulae }\end{array}$ \\
\hline
\end{tabular}

TNF, tumour necrosis factor.

was consensus among the guidelines on most topics, but there were several important areas with contradicting recommendations.

\section{Author contributions}

EJdeG and VNC provided substantial contributions to the conception and design, acquisition of data and analysis and interpretation of data, drafted the article and gave final approval of the version to be published. CJB, DGM, DH and WAB provided substantial contributions to the conception and design, acquisition of data or analysis and interpretation of data, revised the manuscript critically for important intellectual content and gave final approval of the version to be published.

\section{References}

1 Parks AG. Pathogenesis and treatment of fistuila-in-ano. Br Med J 1961; 1: 463-9.

2 Bleier JI, Moloo H, Goldberg SM. Ligation of the intersphincteric fistula tract: an effective new technique for complex fistulas. Dis Colon Rectum 2010; 53: 43-6.

3 Carter MJ, Lobo AJ, Travis SP. Guidelines for the management of inflammatory bowel disease in adults. Gut 2004; 53(Suppl 5): Vl-16.

4 Williams JG, Farrands PA, Williams $\mathrm{AB}$ et al. The treatment of anal fistula: ACPGBI position statement. Colorectal Dis 2007; 9(Suppl 4): 18-50.

5 Sadowski DC, Bernstein CN, Bitton A et al. Canadian Association of Gastroenterology clinical practice guidelines: the use of tumour necrosis factor-alpha antagonist therapy in Crohn's disease. Can J Gastroenterol 2009; 23: 185-202.

6 Brazilian Study Group of Inflammatory Bowel Diseases. Consensus guidelines for the management of inflammatory bowel disease. Arq Gastroenterol 2010; 47: 313-25. 
7 Hvas CL, Dahlerup JF, Jacobsen BA et al. Diagnosis and treatment of fistulising Crohn's disease. Dan Med Bull 2011; 58: C4338.

8 Van AG, Dignass A, Reinisch W et al. The second European evidence-based Consensus on the diagnosis and management of Crohn's disease: special situations. J Crohns Colitis 2010; 4: 63-101.

9 Orlando A, Armuzzi A, Papi C et al. The Italian Society of Gastroenterology (SIGE) and the Italian Group for the study of Inflammatory Bowel Disease (IG-IBD) Clinical Practice Guidelines: the use of tumor necrosis factor-alpha antagonist therapy in inflammatory bowel disease. Dig Liver Dis 2011; 43: 1-20.

10 Ommer A, Herold A, Berg E et al. Cryptoglandular anal fistulas. Dtsch Arztebl Int 2011; 108: 707-13.

11 D'Haens GR, Panaccione R, Higgins PD et al. The London Position Statement of the World Congress of Gastroenterology on Biological Therapy for IBD with the European Crohn's and Colitis Organization: when to start, when to stop, which drug to choose, and how to predict response? Am J Gastroenterol 2011; 106: 199-212.

12 Steele SR, Kumar R, Feingold DL, Rafferty JL, Buie WD. Practice parameters for the management of perianal abscess and fistula-in-ano. Dis Colon Rectum 2011; 54: 1465-74.

13 Gecse KB, Bemelman W, Kamm MA et al. A global consensus on the classification, diagnosis and multidisciplinary treatment of perianal fistulising Crohn's disease. Gut 2014; 63: 1381-92.

14 Ueno F, Matsui T, Matsumoto T et al. Evidence-based clinical practice guidelines for Crohn's disease, integrated with formal consensus of experts in Japan. J Gastroenterol 2013; 48: 31-72.

15 Sahni VA, Ahmad R, Burling D. Which method is best for imaging of perianal fistula? Abdom Imaging 2008; 33: 26-30.

16 West RL, Zimmerman DD, Dwarkasing S et al. Prospective comparison of hydrogen peroxide-enhanced threedimensional endoanal ultrasonography and endoanal magnetic resonance imaging of perianal fistulas. Dis Colon Rectum 2003; 46: 1407-15.

17 Buchanan GN, Halligan S, Bartram CI et al. Clinical examination, endosonography, and MR imaging in preoperative assessment of fistula in ano: comparison with outcome-based reference standard. Radiology 2004; 233: 674-81.

18 Ratto C, Grillo E, Parello A, Costamagna G, Doglietto GB. Endoanal ultrasound-guided surgery for anal fistula. Endoscopy 2005; 37: 722-8.

19 Schwartz DA, Wiersema MJ, Dudiak KM et al. A comparison of endoscopic ultrasound, magnetic resonance imaging, and exam under anesthesia for evaluation of Crohn's perianal fistulas. Gastroenterology 2001; 121: 1064-72.

20 McKee RF, Keenan RA. Perianal Crohn's disease-is it all bad news? Dis Colon Rectum 1996; 39: 136-42.

21 West RL, Dwarkasing S, Felt-Bersma RJ et al. Hydrogen peroxide-enhanced three-dimensional endoanal ultra- sonography and endoanal magnetic resonance imaging in evaluating perianal fistulas: agreement and patient preference. Eur J Gastroenterol Hepatol 2004; 16: 1319-24.

22 Regueiro M. The role of endoscopy in the evaluation of fistulizing Crohn's disease. Gastrointest Endosc Clin N Am 2002; 12: 621-33.

23 Haggett PJ, Moore NR, Shearman JD et al. Pelvic and perineal complications of Crohn's disease: assessment using magnetic resonance imaging. Gut 1995; 36: 40710.

24 Schwartz DA, Loftus EV Jr, Tremaine WJ et al. The natural history of fistulizing Crohn's disease in Olmsted County, Minnesota. Gastroenterology 2002; 122: 875-80.

25 Bell SJ, Williams AB, Wiesel P et al. The clinical course of fistulating Crohn's disease. Aliment Pharmacol Ther 2003; 17: 1145-51.

26 Kuijpers HC, Schulpen T. Fistulography for fistula-in-ano. Is it useful? Dis Colon Rectum 1985; 28: 103-4.

27 Weisman RI, Orsay CP, Pearl RK, Abcarian H. The role of fistulography in fistula-in-ano. Report of five cases. Dis Colon Rectum 1991; 34: 181-4.

28 Schaefer O, Lohrmann C, Langer M. Assessment of anal fistulas with high-resolution subtraction MR-fistulography: comparison with surgical findings. J Magn Reson Imaging 2004; 19: 91-8.

29 Parks AG, Gordon PH, Hardcastle JD. A classification of fistula-in-ano. Br J Surg 1976; 63: 1-12.

30 Quah HM, Tang CL, Eu KW, Chan SY, Samuel M. Meta-analysis of randomized clinical trials comparing drainage alone vs primary sphincter-cutting procedures for anorectal abscess-fistula. Int $J$ Colorectal Dis 2006; 21 : $602-9$.

31 Williams JG, Rothenberger DA, Nemer FD, Goldberg SM. Fistula-in-ano in Crohn's disease. Results of aggressive surgical treatment. Dis Colon Rectum 1991; 34: 378-84.

32 Levien DH, Surrell J, Mazier WP. Surgical treatment of anorectal fistula in patients with Crohn's disease. Surg Gynecol Obstet 1989; 169: 133-6.

33 Hamalainen KP, Sainio AP. Cutting seton for anal fistulas: high risk of minor control defects. Dis Colon Rectum 1997; 40: 1443-6.

34 Garcia-Aguilar J, Belmonte C, Wong DW, Goldberg SM, Madoff RD. Cutting seton versus two-stage seton fistulotomy in the surgical management of high anal fistula. $\mathrm{Br} J$ Surg 1998; 85: 243-5.

35 Zbar AP, Ramesh J, Beer-Gabel M, Salazar R, Pescatori $\mathrm{M}$. Conventional cutting vs. internal anal sphincter-preserving seton for high trans-sphincteric fistula: a prospective randomized manometric and clinical trial. Tech Coloproctol 2003; 7:89-94.

36 Williams JG, MacLeod CA, Rothenberger DA, Goldberg SM. Seton treatment of high anal fistulae. Br J Surg 1991; 78: 1159-61.

37 Lindsey I, Smilgin-Humphreys MM, Cunningham C, Mortensen NJ, George BD. A randomized, controlled trial of fibrin glue vs. conventional treatment for anal fistula. Dis Colon Rectum 2002; 45: 1608-15. 
38 Hyder SA, Travis SP, Jewell DP, McC Mortensen NJ, George BD. Fistulating anal Crohn's disease: results of combined surgical and infliximab treatment. Dis Colon Rectum 2006; 49: 1837-41.

39 Buchanan GN, Owen HA, Torkington J et al. Long-term outcome following loose-seton technique for external sphincter preservation in complex anal fistula. $\mathrm{Br} J$ Surg 2004; 91: 476-80.

40 Ortiz H, Marzo J, Ciga MA et al. Randomized clinical trial of anal fistula plug versus endorectal advancement flap for the treatment of high cryptoglandular fistula in ano. BrJ Surg 2009; 96: 608-12.

41 Mitalas LE, Gosselink MP, Zimmerman DD, Schouten WR. Repeat transanal advancement flap repair: impact on the overall healing rate of high transsphincteric fistulas and on fecal continence. Dis Colon Rectum 2007; 50: 1508-11.

42 Perez F, Arroyo A, Serrano P et al. Randomized clinical and manometric study of advancement flap versus fistulotomy with sphincter reconstruction in the management of complex fistula-in-ano. Am J Surg 2006; 192: $34-40$.

43 Soltani A, Kaiser AM. Endorectal advancement flap for cryptoglandular or Crohn's fistula-in-ano. Dis Colon Rectum 2010; 53: 486-95.

44 Schouten WR, Zimmerman DD, Briel JW. Transanal advancement flap repair of transsphincteric fistulas. Dis Colon Rectum 1999; 42: 1419-22.

45 Ellis CN, Clark S. Fibrin glue as an adjunct to flap repair of anal fistulas: a randomized, controlled study. Dis Colon Rectum 2006; 49: 1736-40.

46 Swinscoe MT, Ventakasubramaniam AK, Jayne DG. Fibrin glue for fistula-in-ano: the evidence reviewed. Tech Coloproctol 2005; 9: 89-94.

47 Schwandner O, Stadler F, Dietl O, Wirsching RP, Fuerst A. Initial experience on efficacy in closure of cryptoglandular and Crohn's transsphincteric fistulas by the use of the anal fistula plug. Int J Colorectal Dis 2008; 23: 31924.

48 Ellis CN, Rostas JW, Greiner FG. Long-term outcomes with the use of bioprosthetic plugs for the management of complex anal fistulas. Dis Colon Rectum 2010; 53: 798 802.

49 Song WL, Wang ZJ, Zheng Y, Yang XQ, Peng YP. An anorectal fistula treatment with acellular extracellular matrix: a new technique. World J Gastroenterol 2008; 14: 4791-4.

50 Rojanasakul A, Pattanaarun J, Sahakitrungruang C, Tantiphlachiva $\mathrm{K}$. Total anal sphincter saving technique for fistula-in-ano; the ligation of intersphincteric fistula tract. $J$ Med Assoc Thai 2007; 90: 581-6.

51 Abcarian AM, Estrada JJ, Park J et al. Ligation of intersphincteric fistula tract: early results of a pilot study. Dis Colon Rectum 2012; 55: 778-82.

52 Yamamoto T, Allan RN, Keighley MR. Effect of fecal diversion alone on perianal Crohn's disease. World J Surg 2000; 24: 1258-62.
53 Guillem JG, Roberts PL, Murray JJ et al. Factors predictive of persistent or recurrent Crohn's disease in excluded rectal segments. Dis Colon Rectum 1992; 35: 768-72.

54 Rehg KL, Sanchez JE, Krieger BR, Marcet JE. Fecal diversion in perirectal fistulizing Crohn's disease is an underutilized and potentially temporary means of successful treatment. Am Surg 2009; 75: 715-8.

55 Galandiuk S, Kimberling J, Al-Mishlab TG, Stromberg AJ. Perianal Crohn disease: predictors of need for permanent diversion. Ann Surg 2005; 241: 796-801.

56 Dewint P, Hansen BE, Verhey E et al. Adalimumab combined with ciprofloxacin is superior to adalimumab monotherapy in perianal fistula closure in Crohn's disease: a randomised, double-blind, placebo controlled trial (ADAFI). Gut 2014; 63: 292-9.

57 Maeda Y, Ng SC, Durdey P et al. Randomized clinical trial of metronidazole ointment versus placebo in perianal Crohn's disease. Br J Surg 2010; 97: 1340-7.

58 Pearson DC, May GR, Fick GH, Sutherland LR. Azathioprine and 6-mercaptopurine in Crohn disease. A metaanalysis. Ann Intern Med 1995; 123: 132-42.

59 Thia KT, Mahadevan U, Feagan BG et al. Ciprofloxacin or metronidazole for the treatment of perianal fistulas in patients with Crohn's disease: a randomized, doubleblind, placebo-controlled pilot study. Inflamm Bowel Dis 2009; 15: 17-24.

60 Prefontaine E, Macdonald JK, Sutherland LR. Azathioprine or 6-mercaptopurine for induction of remission in Crohn's disease. Cochrane Database Syst Rev 2010; 6: CD000545.

61 Present DH, Korelitz BI, Wisch N et al. Treatment of Crohn's disease with 6-mercaptopurine. A long-term, randomized, double-blind study. N Engl J Med 1980; 302: 981-7.

62 Sandborn WJ, Fazio VW, Feagan BG, Hanauer SB. AGA technical review on perianal Crohn's disease. Gastroenterology 2003; 125: 1508-30.

63 Present DH, Rutgeerts P, Targan S et al. Infliximab for the treatment of fistulas in patients with Crohn's disease. N Engl J Med 1999; 340: 1398-405.

64 Behm BW, Bickston SJ. Tumor necrosis factor-alpha antibody for maintenance of remission in Crohn's disease. Cochrane Database Syst Rev 2008; 1: CD006893.

65 Sands BE, Anderson FH, Bernstein CN et al. Infliximab maintenance therapy for fistulizing Crohn's disease. $N$ Engl J Med 2004; 350: 876-85.

66 Colombel JF, Schwartz DA, Sandborn WJ et al. Adalimumab for the treatment of fistulas in patients with Crohn's disease. Gut 2009; 58: 940-8.

67 Hanauer SB, Smith MB. Rapid closure of Crohn's disease fistulas with continuous intravenous cyclosporin A. Am J Gastroenterol 1993; 88: 646-9.

68 Present DH, Lichtiger S. Efficacy of cyclosporine in treatment of fistula of Crohn's disease. Dig Dis Sci 1994; 39: 374-80.

69 Egan LJ, Sandborn WJ, Tremaine WJ. Clinical outcome following treatment of refractory inflammatory and fis- 
tulizing Crohn's disease with intravenous cyclosporine. Am J Gastroenterol 1998; 93: 442-8.

70 Sandborn WJ, Present DH, Isaacs KL et al. Tacrolimus for the treatment of fistulas in patients with Crohn's disease: a randomized, placebo-controlled trial. Gastroenterology 2003; 125: 380-8.

71 Orsoni P, Barthet M, Portier F et al. Prospective comparison of endosonography, magnetic resonance imaging and surgical findings in anorectal fistula and abscess complicating Crohn's disease. Br J Surg 1999; 86: 360-4.

$72 \mathrm{Wu}$ XW, Ji HZ, Wang FY. Meta-analysis of ciprofloxacin in treatment of Crohn's disease. Biomed Rep 2015; 3: $70-4$.

73 Lichtenstein GR, Yan S, Bala M, Blank M, Sands BE. Infliximab maintenance treatment reduces hospitalizations, surgeries, and procedures in fistulizing Crohn's disease. Gastroenterology 2005; 128: 862-9.

74 Hart AL, Plamondon S, Kamm MA. Topical tacrolimus in the treatment of perianal Crohn's disease: exploratory randomized controlled trial. Inflamm Bowel Dis 2007; 13: 245-53.

75 Maier AG, Funovics MA, Kreuzer SH et al. Evaluation of perianal sepsis: comparison of anal endosonography and magnetic resonance imaging. J Magn Reson Imaging 2001; 14: 254-60.

76 Halligan S. Imaging fistula-in-ano. Clin Radiol 1998; 53: 85-95.

77 Skalej M, Makowiec F, Weinlich M et al. [Magnetic resonance imaging in perianal Crohn's disease]. Dtsch Med Wochenschr 1993; 118: 1791-6.

78 van Bodegraven AA, Sloots CE, Felt-Bersma RJ, Meuwissen SG. Endosonographic evidence of persistence of Crohn's disease-associated fistulas after infliximab treatment, irrespective of clinical response. Dis Colon Rectum 2002; 45: 39-45.

79 Sloots CE, Felt-Bersma RJ, Poen AC, Cuesta MA, Meuwissen SG. Assessment and classification of fistula-inano in patients with Crohn's disease by hydrogen peroxide enhanced transanal ultrasound. Int J Colorectal Dis 2001; 16: $292-7$.

80 Guillaumin E, Jeffrey RB Jr, Shea WJ, Asling CW, Goldberg HI. Perirectal inflammatory disease: CT findings. Radiology 1986; 161: 153-7.

81 Yousem DM, Fishman EK, Jones B. Crohn disease: perirectal and perianal findings at CT. Radiology 1988; 167: $331-4$.

82 Roig JV, Garcia-Armengol J, Jordan JC et al. Fistulectomy and sphincteric reconstruction for complex cryptoglandular fistulas. Colorectal Dis 2010; 12: el45-52.

83 Scott HJ, Northover JM. Evaluation of surgery for perianal Crohn's fistulas. Dis Colon Rectum 1996; 39: 1039-43.

84 Morrison JG, Gathright JB Jr, Ray JE et al. Surgical management of anorectal fistulas in Crohn's disease. Dis Colon Rectum 1989; 32: 492-6.

85 van der Hagen SJ, Baeten CG, Soeters PB et al. Anti-TNFalpha (infliximab) used as induction treatment in case of active proctitis in a multistep strategy followed by definitive surgery of complex anal fistulas in Crohn's disease: a preliminary report. Dis Colon Rectum 2005; 48: 758-67.

86 van Koperen PJ, Wind J, Bemelman WA et al. Long-term functional outcome and risk factors for recurrence after surgical treatment for low and high perianal fistulas of cryptoglandular origin. Dis Colon Rectum 2008; 51: $1475-81$.

87 van Tets WF, Kuijpers HC. Continence disorders after anal fistulotomy. Dis Colon Rectum 1994; 37: 1194-7.

88 Garcia-Aguilar J, Belmonte C, Wong WD, Goldberg SM, Madoff RD. Anal fistula surgery. Factors associated with recurrence and incontinence. Dis Colon Rectum 1996; 39: 723-9.

89 Davies M, Harris D, Lohana P et al. The surgical management of fistula-in-ano in a specialist colorectal unit. Int $J$ Colorectal Dis 2008; 23: 833-8.

90 Parks AG, Stitz RW. The treatment of high fistula-in-ano. Dis Colon Rectum 1976; 19: 487-99.

91 Faucheron JL, Saint-Marc O, Guibert L, Parc R. Longterm seton drainage for high anal fistulas in Crohn's disease-a sphincter-saving operation? Dis Colon Rectum 1996; 39: 208-11.

92 Topstad DR, Panaccione R, Heine JA et al. Combined seton placement, infliximab infusion, and maintenance immunosuppressives improve healing rate in fistulizing anorectal Crohn's disease: a single center experience. Dis Colon Rectum 2003; 46: 577-83.

93 Ozuner G, Hull TL, Cartmill J, Fazio VW. Long-term analysis of the use of transanal rectal advancement flaps for complicated anorectal/vaginal fistulas. Dis Colon Rectum 1996; 39: 10-4.

94 van Koperen PJ, Wind J, Bemelman WA, Slors JF. Fibrin glue and transanal rectal advancement flap for high transsphincteric perianal fistulas; is there any advantage? Int J Colorectal Dis 2008; 23: 697-701.

95 Hjortrup A, Moesgaard F, Kjaergard J. Fibrin adhesive in the treatment of perineal fistulas. Dis Colon Rectum 1991; 34: 752-4.

96 Adams T, Yang J, Kondylis LA, Kondylis PD. Long-term outlook after successful fibrin glue ablation of cryptoglandular transsphincteric fistula-in-ano. Dis Colon Rectum 2008; 51: 1488-90.

97 Sentovich SM. Fibrin glue for anal fistulas: long-term results. Dis Colon Rectum 2003; 46: 498-502.

98 Vitton V, Gasmi M, Barthet M et al. Long-term healing of Crohn's anal fistulas with fibrin glue injection. Aliment Pharmacol Ther 2005; 21 : 1453-7.

99 Grimaud JC, Munoz-Bongrand N, Siproudhis L et al. Fibrin glue is effective healing perianal fistulas in patients with Crohn's disease. Gastroenterology 2010; 138: 2275-81.

100 O'Connor L, Champagne BJ, Ferguson MA et al. Efficacy of anal fistula plug in closure of Crohn's anorectal fistulas. Dis Colon Rectum 2006; 49: 1569-73.

$101 \mathrm{Ky} \mathrm{AJ,} \mathrm{Sylla} \mathrm{P,} \mathrm{Steinhagen} \mathrm{R} \mathrm{et} \mathrm{al.} \mathrm{Collagen} \mathrm{fistula} \mathrm{plug}$ for the treatment of anal fistulas. Dis Colon Rectum 2008; 51: $838-43$. 
102 Bernstein LH, Frank MS, Brandt LJ, Boley SJ. Healing of perineal Crohn's disease with metronidazole. Gastroenterology 1980; 79: 357-65.

103 Brandt LJ, Bernstein LH, Boley SJ, Frank MS. Metronidazole therapy for perineal Crohn's disease: a follow-up study. Gastroenterology 1982; 83: 383-7.

104 Dejaco C, Harrer M, Waldhoer T et al. Antibiotics and azathioprine for the treatment of perianal fistulas in Crohn's disease. Aliment Pharmacol Ther 2003; 18: 1113-20.

105 West RL, van der Woude CJ, Hansen BE et al. Clinical and endosonographic effect of ciprofloxacin on the treatment of perianal fistulae in Crohn's disease with infliximab: a double-blind placebo-controlled study. Aliment Pharmacol Ther 2004; 20: 1329-36.

106 Korelitz BI, Adler DJ, Mendelsohn RA, Sacknoff AL. Long-term experience with 6-mercaptopurine in the treatment of Crohn's disease. Am J Gastroenterol 1993; 88: 1198-205.

107 Felley C, Mottet C, Juillerat P et al. Fistulizing Crohn's disease. Digestion 2007; 76: 109-12.

108 Colombel JF, Sandborn WJ, Rutgeerts P et al. Adalimumab for maintenance of clinical response and remission in patients with Crohn's disease: the CHARM trial. Gastroenterology 2007; 132: 52-65.

109 Hanauer SB, Sandborn WJ, Rutgeerts P et al. Human anti-tumor necrosis factor monoclonal antibody (adalimumab) in Crohn's disease: the CLASSIC-I trial. Gastroenterology 2006; 130: 323-33.

110 Ford AC, Sandborn WJ, Khan KJ et al. Efficacy of biological therapies in inflammatory bowel disease: systematic review and meta-analysis. Am J Gastroenterol 2011; 106: 644-59, quiz.

\section{Appendix}

\section{PubMed on 30 September 2015 - 235 hits}

1 ('Rectal fistula'[Mesh] OR perianal fistul* [tiab] OR peri-anal fistul*[tiab] OR rectal fistul*[tiab] OR anorectal fistul*[tiab] OR anus fistul*[tiab] OR anal fistul* [tiab] OR rectum fistul*[tiab] OR rectal fistul* [tiab]) OR ('Crohn Disease'[MeSH] AND guideline*[ti]) OR ('Crohn Disease' $[\mathrm{MeSH}]$ AND consensus*[ti]) OR (fistulising crohn*[ti])

2 ('Guideline' [Publication Type] OR 'Guidelines as Topic'[Mesh] OR 'Guideline Adherence'[Mesh] OR 'Practice Guideline' [Publication Type] OR 'Consensus'[Mesh] OR 'Consensus Development Conferences as Topic'[Mesh] OR practice parameter*[tiab] OR consensus* [tiab] OR guideline* [tiab] OR 'Consensus Development Conference, NIH' [Publication Type] OR 'Consensus Development Conference'
[Publication Type] OR 'Consensus Development Conferences, NIH as Topic'[Mesh] OR (fistulising crohn*[ti] AND 'Review'[pt]))

3 ('Case Reports' [Publication Type] OR 'Letter' [Publication Type] OR 'Newspaper Article' [Publication Type])

41 and 2

54 not 3

\section{EMBASE on 30 September 2015 - 197 hits}

1 anus fistula/

2 perianal fistul* or peri-anal fistul* or rectal fistul* or anorectal fistul* or anus fistul* or anal fistul* or fistula ani or rectum fistul* or fistula recti or rectal fistul* $^{*}$ ti, ab, kw.

3 Crohn disease/and guideline*.ti.

41 or 2 or 3

5 exp practice guideline/

6 consensus development/

7 consensus/

8 practice parameter* or consensus* or guideline*.mp.

9 fistulising crohn*.ti and 'review' /

105 or 6 or 7 or 8 or 9

114 and 10

12 case report/or letter/or publication

1311 not 12

\section{MEDLINE on 30 September 2015 - 80 hits}

1 exp Rectal Fistula/

2 perianal fistul* or peri-anal fistul* or rectal fistul* or anorectal fistul* or rectovaginal fistul* or anus fistul $^{*}$ or anal fistul* or fistula ani or rectum fistul* or fistula recti or rectal fistul*).ti,ab,kw.

3 Crohn disease/and (guideline* or consensus*).ti.

41 or 2 or 3

5 exp Practice Guideline/or exp Guideline Adherence/or exp Guideline/or consensus/or exp Guidelines as Topic/

6 practice parameter* or consensus* or guideline*).mp.

7 fistulising crohn*.ti. and 'review' /

85 or 6 or 7

94 and 8

10 case reports/or letter/or newspaper article/

119 not 10 